\title{
Effect of Acid Hydrolysis on Tableting Properties of Chitin Obtained from Shrimp Heads
}

\author{
John Rojas*, Juliana Madrigal and Juliana Ortiz \\ Department of Pharmacy, School of Pharmaceutical Chemistry, The University of Antioquia, Medellin, Columbia, CII 67 \# 53- \\ 108, off. 1-157. Medellin, Columbia \\ *For correspondence: Email: jrojasca@gmail.com
}

\begin{abstract}
Purpose: To assess the effect of acid hydrolysis on the degree of acetylation, crystallinity, and molecular weight of chitin obtained from shrimp heads as well as to evaluate their tableting properties. Methods: The effect of acid hydrolysis conditions such as reaction temperature (46, 60, 80, 100 , $\left.114^{\circ} \mathrm{C}\right)$, hydrochloric acid concentration $(4.6,6,8,10$ and $11.4 \mathrm{M})$ and reaction time $(0.6,2,4,6$ and 7.4 h) were examined. The degree of acetylation and molecular weight were found by Fourier transform spectroscopy (FT-IR) and viscometry methods, respectively. The degree of crystallinity degree and its compact tensile strength were determined by $x$-ray and Fell \& Newton methods, respectively.

Results: The combined effect of high temperature $\left(>80^{\circ} \mathrm{C}\right), \mathrm{HCl}$ concentration $(>2 \mathrm{M})$ and reaction time $(>4 \mathrm{~h}$ ) led to high depolymerization, reduction in degree of acetylation, crystallinity, chitin yield and thus, decreased tensile strength and accelerated compact disintegration time. Optimal reaction conditions were achieved at an acid concentration of $2.2 \mathrm{M}$, temperature of $60^{\circ} \mathrm{C}$ and reaction time of 4 $h$. These conditions rendered compacts with tensile strength of 25.7 MPa and disintegration time of 25.3 $\min$.

Conclusion: The optimal $\mathrm{HCl}$ hydrolysis conditions for shrimp heads rendered chitin suitable for the preparation of compacts with good tensile strength and moderate disintegration time.
\end{abstract}

Keywords: Chitin, Compressibility, Deacetylation, Acid hydrolysis, Tableting performance, Central composite design.

\begin{abstract}
Tropical Journal of Pharmaceutical Research is indexed by Science Citation Index (SciSearch), Scopus, International Pharmaceutical Abstract, Chemical Abstracts, Embase, Index Copernicus, EBSCO, African Index Medicus, JournalSeek, Journal Citation Reports/Science Edition, Directory of Open Access Journals (DOAJ), African Journal Online, Bioline International, Open-J-Gate and Pharmacy Abstracts
\end{abstract}

\section{INTRODUCTION}

Chitin is the poly- $\beta$-(1-4)-N-acetyl-D-glucosamine polymer found in the exoskeleton of a wide variety of invertebrates such as crustaceans, insects and in the cell wall of fungi and yeast [1]. Chitin has a structural function comparable to that of collagen in higher animals and cellulose in terrestrial plants. It occurs in nature as ordered crystalline microfibrils associated to proteins. It possesses excellent biocompatibility; it is ecologically safe and has a very low toxicity [2]. Chitin is extracted by acid treatment to dissolve calcium carbonate, followed by an alkaline extraction to eliminate fats and a final depigmentation process [3]. In chitin, the degree of acetylation (DA) is > $50 \%$ indicating the presence of some amino groups in its structure (C-2) since some deacetylation might take place during extraction. When the degree of acetylation is $<50 \%$ it is regarded as chitosan [4].

Currently, natural or semisynthetic excipients such as lactose, microcrystalline cellulose (MCC), calcium diphosphate, starch and sorbitol are used to prepare solid dosage forms. They 
are mostly used as diluents for drugs when formulating tablets for immediate release of drugs. These tablets are prepared by direct compression, dry granulation or wet granulation. However, only MCC can be used alone for direct compression due to its good mechanical properties.

For this reason, it is important to look for new biodegradable and biocompatible excipients such as chitin to produce tablets. It is possible that chitin depolymerization causes changes on the degree of crystallinity and hence, this could affect its tableting properties.

Therefore, the objective of this work is to study the effect of $\mathrm{HCl}$ hydrolysis conditions on tableting properties such as tensile strength and disintegration of compact and other polymer properties such as degree of acetylation, degree of crystallinity, and molecular weight of chitin.

\section{EXPERIMENTAL}

\section{Chemicals}

Shrimp exoskeletons were purchased from Comerpes SA (Cartagena, Columbia). Sodium hydroxyde (lot B064398119) was obtained from Merck (Darmstadt, Germany), concentrated hydrochloric acid (lot 3024) and sodium hypochlorite (lot 1791) were purchased from JM chemicals (Medellin, Columbia).

\section{Experimental design}

A Central Composite Design (CCD) with 20 runs was used to assess the effect of acid hydrolysis conditions such as temperature $(60,80$ and 100 $\left.{ }^{\circ} \mathrm{C}\right)$, concentration $(1.7,2.2$ and $2.7 \mathrm{M}$ ) and reaction time $(2,4$ and $6 \mathrm{~h})$ on properties of chitin such as acetylation degree, molecular weight and yield. The effect of acid treatment on compact tensile strength and disintegration time was also investigated. In order to explore the largest experimental space, an alpha distant of +1.682 from the center was used. The validity of this model was tested with the ANOVA analysis, lack of fit test and a new validation run. The levels of each factor and the conditions of the acid hydrolysis are shown in Table 1.The Design Expert software (vs. 8.04, Stat-Ease, Inc, Minneapolis, MN) was used for the data analysis.

\section{Production of chitin}

Approximately, $20 \mathrm{~g}$ of dry exoskeletons were milled on a cutting mill (Model 3, Willey, Arthur Thomas Co., Philadelphia, USA), passed through a \# 16 mesh sieve and hydrolyzed at the conditions shown in Table 1 using a heating mantle (P\&P, Medellin, Columbia) coupled with a round bottom flask and a two-decked condenser. The solid-to-HCl solution ratio was (1:10).

The dispersion was then neutralized with a $3 \mathrm{M}$ sodium hydroxide solution, filtered and dried in anoven (U50, Memmert, Schawabach, Germany) at $100{ }^{\circ} \mathrm{C}$ for $3 \mathrm{~h}$.

Table 1: Experimental matrix for the acid hydrolysis conditions according to the Central Composite Design

\begin{tabular}{llllllllll}
\hline Run & $\begin{array}{l}\text { Con } \\
(\mathbf{M})\end{array}$ & $\begin{array}{l}\text { Temp } \\
\left({ }^{\circ} \mathbf{C}\right)\end{array}$ & $\begin{array}{l}\text { Tim } \\
(\mathbf{m i n})\end{array}$ & $\begin{array}{l}\text { Yield } \\
(\%)\end{array}$ & $\begin{array}{l}\text { AD } \\
(\%)\end{array}$ & $\begin{array}{l}\text { MW } \\
(\mathbf{D a})\end{array}$ & $\begin{array}{l}\text { DC } \\
(\%)\end{array}$ & $\begin{array}{l}\text { TS } \\
(\mathbf{M P a})\end{array}$ & $\begin{array}{l}\text { DT } \\
(\mathbf{m i n})\end{array}$ \\
\hline 1 & 8 & 80 & 4 & 8.4 & 62.6 & 104765 & 45.3 & 5.9 & 29.3 \\
2 & 4.6 & 80 & 4 & 10.9 & 67.2 & 36352.5 & 65.6 & 4.8 & 37.5 \\
3 & 8 & 46 & 4 & 12 & 63.8 & 62592.7 & 51.7 & 5.4 & 20.5 \\
4 & 6 & 60 & 6 & 9.8 & 58.2 & 46349.9 & 56.8 & 5.8 & 45.7 \\
5 & 8 & 80 & 4 & 9.8 & 62.9 & 109768 & 43.2 & 5.4 & 29.3 \\
6 & 8 & 80 & 4 & 7.7 & 64.3 & 107875 & 41.6 & 4.6 & 22.5 \\
7 & 8 & 80 & 4 & 10.6 & 63.1 & 108915 & 43.4 & 4.7 & 20.7 \\
8 & 8 & 80 & 7.4 & 11.7 & 60.2 & 108288 & 32 & 5.7 & 27.9 \\
9 & 6 & 60 & 2 & 10.2 & 59.0 & 45668.5 & 51.6 & 4.7 & 65.3 \\
10 & 8 & 80 & 4 & 11.4 & 61.7 & 107715 & 44.7 & 5.8 & 26.8 \\
11 & 11.4 & 80 & 4 & 8.8 & 52.5 & 218348 & 35.6 & 6.2 & 18.4 \\
12 & 8 & 114 & 7.4 & 7.2 & 60.3 & 152838 & 28.3 & 5.4 & 2.54 \\
13 & 6 & 100 & 6 & 9.8 & 63.7 & 76806.3 & 38.2 & 4.4 & 15.4 \\
14 & 8 & 80 & 4 & 11.7 & 61.2 & 112735 & 44.3 & 5.1 & 24.8 \\
15 & 6 & 100 & 2 & 15.4 & 58.5 & 76124.9 & 55.8 & 4.8 & 12.8 \\
16 & 10 & 100 & 6 & 9.1 & 58.6 & 210801 & 22.8 & 6.6 & 7.6 \\
17 & 8 & 80 & 0.6 & 66.4 & 62.7 & 107143 & 54 & 3.4 & 50.3 \\
18 & 10 & 100 & 2 & 14.3 & 51.9 & 210120 & 39.3 & 5.6 & 43.1 \\
19 & 10 & 60 & 6 & 7.9 & 53 & 126814 & 28.4 & 4.2 & 55.4 \\
20 & 10 & 60 & 2 & 9.4 & 67.2 & 126133 & 46.9 & 5.1 & 76.5 \\
\hline
\end{tabular}


The dry material was then hydrolyzed with a $3 \mathrm{M}$ sodium hydroxide at $100{ }^{\circ} \mathrm{C}$ for $4 \mathrm{~h}$ to decompose proteins, fats and pigments. This dispersion was then neutralized with $8 \% \mathrm{HCl}$, vacuum filtered and treated with a $15 \% \mathrm{w} / \mathrm{v}$ sodium hypochlorite for $24 \mathrm{~h}$ at a 1:2 solid-to$\mathrm{NaClO}$ ratio to remove traces of pigments. The resulting material was then washed until a conductivity of $<20 \mu \mathrm{S} / \mathrm{cm}$ was reached and filtered. The cake product was dried at $60{ }^{\circ} \mathrm{C}$ for $24 \mathrm{~h}$ and passed through a \#100 mesh sieve.

\section{Degree of acetylation}

Approximately, $1.5 \mathrm{mg}$ of sample was mixed with $200 \mathrm{mg}$ of dry $\mathrm{KBr}$ (previously dried at $110^{\circ} \mathrm{C}$ for $4 \mathrm{~h})$ with an agate mortar and pestle. The powdered sample was compressed into a pellet using a $13 \mathrm{~mm}$ flat-faced punch and die tooling, fitted on a portable press at a dwell time of five min. A Perkin-Elmer spectrophotometer (Perkin Elmer, CA, USA) equipped with the Spectra software (Spectrum BX, vs. 5.3.1, Perkin Elmer, Inc, CA, USA) was used to obtain the spectra between 400 and $4000 \mathrm{~cm}^{-1}$. The resolution, interval length and number of scans employed were 16, 2.0 and $16 \mathrm{~cm}^{-1}$, respectively. The acetylation degree was found by applying the method of Baxter and collaborators by taking the ratio of the absorbances of the FT-IR bands obtained at 1660 and $3450 \mathrm{~cm}^{-1}$, respectively, as shown in Eq 1 [5].

$D A=100-\left[\left(A_{1660} / A_{3450}\right) / 1.33\right] \times 100 \ldots \ldots(1)$

where, $A_{1660}$ and $A_{3450}$ correspond to the type I amide and hydroxyl stretching band, respectively.

\section{Powder yield}

It was determined on a dry basis dividing the amount of chitin obtained from each experimental run by 20 and multiplying by $100 \%$.

\section{Molecular weight determination (M்V)}

It was determined by capillary viscometry by dissolving $250 \mathrm{mg}$ of chitin in $50 \mathrm{~mL}$ of $25 \%$ $\mathrm{NaOH}$. The chitin concentrations used for the analysis $0.02,0.1,0.3$ and $0.6 \mathrm{~g} / \mathrm{dL}$ were prepared individually. Samples were sonicated for $45 \mathrm{~min}$ before testing. A Canon-Fenske capillary viscometer was immersed in a water bath, equipped with a temperature controller set at $25^{\circ} \mathrm{C}$. Approximately, $8 \mathrm{~mL}$ of the solution was employed per sample. The intrinsic viscosity [n] was obtained from Eq 2.

$\left\{\left[\left(t / t_{o}\right)-1\right] / C\right\}=100[\eta]+k C$ where, $t$ and $t_{0}$ are the efflux times of the chitin solution and the solvent, respectively. All samples were analyzed in triplicates.

\section{Degree of crystallinity (DC)}

It was determined by powder X-ray diffractometry conducted over a 5 to $45^{\circ} 2 \theta$ range. A Rigaku diffractometer (Miniflex II, Rigaku, Americas, Woodlands, TX) operated at $40 \mathrm{kV}$ and $30 \mathrm{~mA}$ equipped with a monochromatic CuKa $\left(\alpha_{1}=\right.$ $1.5460 \AA, \alpha_{2}=1.54438 \AA$ ) X-ray radiation was employed for the analysis. The sweep speed and step width were $0.5^{\circ} 2 \theta / \mathrm{min}$ and 0.0080 , respectively. The DC was calculated from the Peakfit software (Seasolve, Inc, Framingham, MA) by separating the crystalline $\left(I_{110}\right)$ and amorphous $\left(\mathrm{I}_{\mathrm{am}}\right)$ scattering radiation using the baseline selection. Eq 3 was used.

$D C=\left[\left(I_{110}-I_{A M}\right) / I_{110}\right] \times 100$

where, $I_{110}$ is the area of the diffracted main peak at $19.2 \circ 2 \theta$ and $I_{a m}$ is the area of the diffuse halo due to the amorphous region [6].

\section{Compact tensile strength (TS)}

Cylindrical compacts of about $100 \mathrm{mg}$ and 6.5 $\mathrm{mm}$ in diameter were made at rapproximately 430 psi and a dwell time of $1 \mathrm{~s}$. A single punch tablet press (060804 Compac, Indemec, Itagui, Columbia) equipped with a load cell (LCGD-10K, Omega Engineering, Inc., Stamford, CT) was employed. The data of crushing strength values obtained on a hardness tester (UK 200, Vankel, Manasquan, NJ) were transformed to tensile strength according to the Fell and Newton model [7].

\section{Compact disintegration time (DT)}

Tablets, each weighing about $100 \mathrm{mg}$, were made on a single punch tablet press (060804 Compac, Indemec, Itagui, Columbia) at approximately 100 psi using a $6.5 \mathrm{~mm}$ round flatfaced punches and die set and a dwell time of 1s. Five replicate were tested in distilled water at $37^{\circ} \mathrm{C}$ employing a Hanson disintegrator (39-133115, Hanson Research Corporation, Northridge, CA, USA) operating at 30 strokes/min.

\section{RESULTS}

The effect of the degree of hydrolysis on the material and tableting properties of chitin is shown in Table 1. Except for chitin yield, all properties decrease with increasing temperature, $\mathrm{HCl}$ concentration and reaction time. Concentration, temperature and time were 
significant factors $(p<0.02)$ for chitin yield, acetylation degree and degree of crystallinity. However, only the reaction time was significant for tensile strength $(p=0.03)$. Likewise, concentration and reaction time were significant $(p<0.02)$ for molecular weight and compact disintegration. This means that a large molecular weight is a condition for a compact to have a large disintegration time and tensile strength. Thus, a large molecular weight make the polymer chains able to get closer upon compaction forming a tight hydrogen bonding network, which is boosted by the polymer length. As a result, it is more difficult for water to penetrate and disrupt this particle-particle interaction and hydrogen bonding and hence, the compact disintegration time is prolonged.

The cubic models obtained from the CCD summarize the properties studied and are depicted in Figures 1 and 2. The determination coefficients were higher than 0.9498 indicating a good fit of the data to the cubic models and hence, a good relationship between the variables and the responses studied. The cubic models are shown in the following equations:

$1 /$ yield $=0.099+0.006 \mathrm{~A}+0.017 \mathrm{~B}+0.021 \mathrm{C}+$ $0.007 B C+0.006 B^{2}-0.015 C^{2}-0.027 A^{2} B$

$r^{2}=0.9594$

$A D=46.4-7.93 A-4.83 B-2.99 B C+2.26 B^{2}+$ $9.21 \mathrm{ABC}-4.21 \mathrm{~A}^{2} \mathrm{C} \quad \mathrm{r}^{2}=0.9498 \ldots \ldots$ (5)

$1 / \mathrm{TS}=0.19+0.017 \mathrm{C}-0.019 \mathrm{AB}+0.015 \mathrm{C}^{2}-$ $0.016 A B C-0.019 C^{3} \quad r^{2}=0.9594$

$\mathrm{MW}=612283.9-154820 \mathrm{~A}-170361 \mathrm{C}-$ $279673 A^{2} B \quad r^{2}=0.9667$

$\mathrm{DT}=30.4-12.8 \mathrm{~A}+1.69 \mathrm{~B}+16.3+2.25 \mathrm{AB}-$ $5.21 A C+9.1 B C+1.23 A^{2}-2.88 B^{2}+8.99 C^{2}-$ $6.59 A B C-19.6 A^{2} B-31.33 A^{2} C+13.68 A B^{2}$

$r^{2}=0.9882$
$\mathrm{DC}=43.8-8.92 \mathrm{~A}-6.96 \mathrm{~B}-6.54 \mathrm{C}+0.15 \mathrm{AB}-$ $2.83 A C-2.6 B C+1.98 A^{2}-1.77 B^{2}-0.71 C^{2}+$ $3.1 A B C+3.51 A^{2} B+0.62 A^{2} C+0.79 A B^{2}$

$r^{2}=0.9557$

In general, large acid concentrations, high concentrations of acid and long reaction times were reflected in a product with a high depolymerization, deacetylation, low chitin yield and crystallinity and resulted in compacts of low tensile strength and short disintegration times.

\section{DISCUSSION}

During the acid hydrolysis, degradation of the polymeric chains took place. A high deacetylation occurred by using harsh reaction conditions such as a high acid concentration $>1.3 \mathrm{M}$ and temperatures higher than $46{ }^{\circ} \mathrm{C}$. The varying degrees of acetylation of chitin indicates that the acetamide groups were partially eliminated indicating that the acid hydrolysis conditions were drastic enough to also break down the acetamide linkage besides the contribution of the alkali. It is inferred that $\mathrm{HCl}$ besides breaking the $\beta-1-4$ bonds also broke the acetyl bonds, especially at prolonged reaction times. Therefore, high reaction temperatures and acid concentrations led to a decrease in the acetylation degree. Furthermore, the acid hydrolysis led to a partial depolymerization resulting in a reduced molecular weight $(\sim 36$ to $220 \mathrm{kDa}$ ) (Table 2). For this reason, a combination of a large reaction time, concentration and temperature led to a large reduction in molecular weight and deacetylation. Furthermore, a low hydrolysis time and acid concentration hardly reduced the acetylation degree and the resulting molecular weight. For this reason, the reduction of the reaction time and temperature minimized the degradation of the polymer chains resulting in a larger molecular weight.

Table 2: Effect of hydrolysis conditions on the material and tableting properties of chitin

\begin{tabular}{|c|c|c|c|}
\hline $\begin{array}{l}\text { Chitin } \\
\text { property }\end{array}$ & $\begin{array}{c}\text { Soft hydrolysis conditions } \\
\mathrm{HCl} \text { concentration: } 6 \mathrm{M} \\
\text { Time: } 2 \mathrm{~h} \\
\text { Temperature: } 60^{\circ} \mathrm{C}\end{array}$ & $\begin{array}{c}\text { Moderate conditions } \\
\mathrm{HCl} \text { concentration: } 8 \mathrm{M} \\
\text { Time: } 4 \mathrm{~h} \\
\text { Temperature: } 80^{\circ} \mathrm{C}\end{array}$ & $\begin{array}{c}\text { Harsh hydrolysis conditions } \\
\text { HCl concentration: } 10 \mathrm{M} \\
\text { Time: } 6 \mathrm{~h} \\
\text { Temperature: } 100^{\circ} \mathrm{C}\end{array}$ \\
\hline $\mathrm{AD}(\%)$ & 55.2 & 45.4 & 34.1 \\
\hline $\mathrm{DC}(\%)$ & 53.6 & 42.3 & 22.1 \\
\hline DT (min) & 80.5 & 30.5 & 7.2 \\
\hline $\mathrm{MW}(\mathrm{kDa})$ & 200.5 & 107.2 & 45.2 \\
\hline TS (MPa) & 4.5 & 5.3 & 6.5 \\
\hline Yield (\%) & 12.1 & 9.5 & 9.1 \\
\hline
\end{tabular}




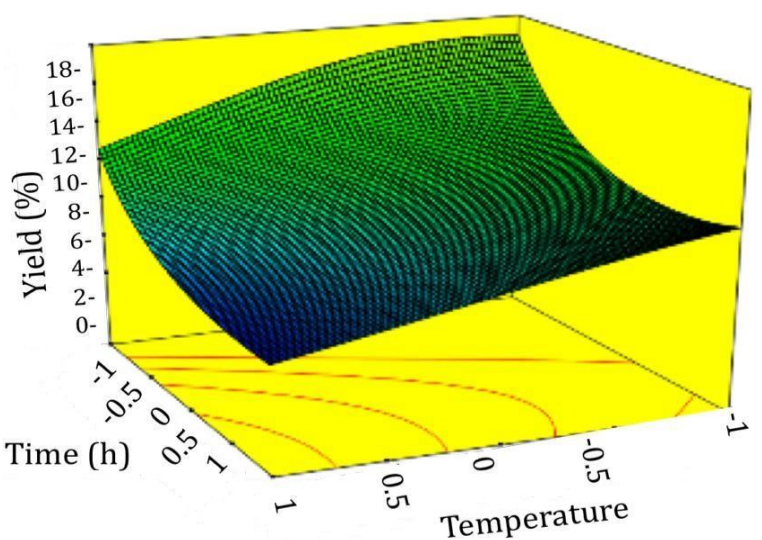

(C)
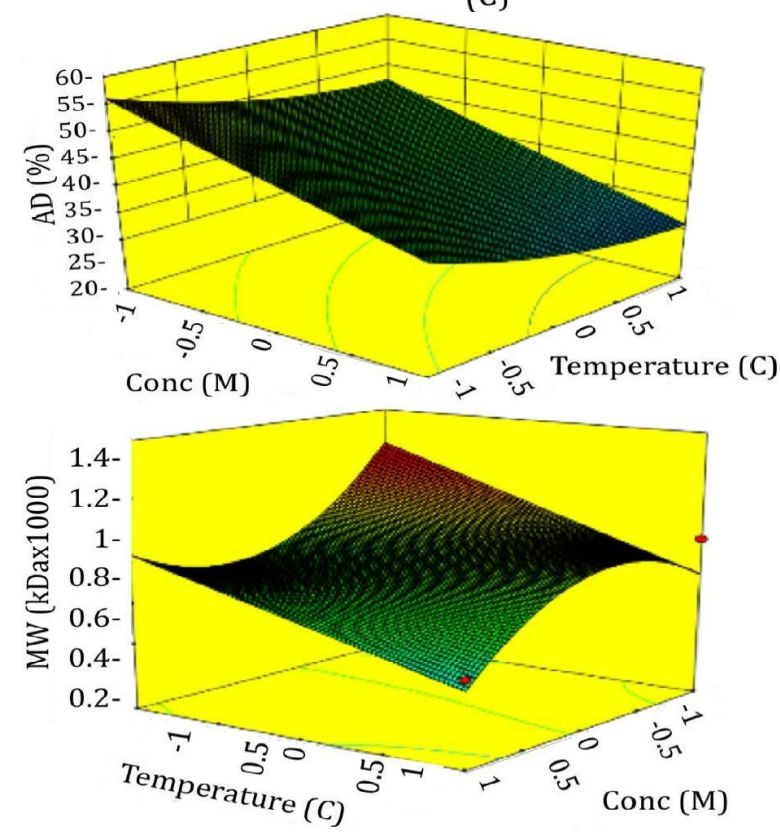

Figure 1: Surface response plots for (a) Y: yield, (b) $A D$ : acetylation degree, and (c) MW: molecular weight

A high acid concentration and temperature led to a depolymerization of chitin. This result is similar to others reported previously [8] where a first order kinetics for depolymerization and hydrolysis of glycosidic bonds was observed. On the contrary, the deacetylation reaction (Figure 3) was only moderately influenced by the acid concentration because the acid mainly attacks the $\beta-1-4$ linkage from the amorphous regions and in a lower degree the acetamide group linked in the C-2 carbon.

It is widely accepted that the deacetylation reaction usually happens under basic conditions, but this study showed it also happens at acid conditions. Therefore, $\mathrm{HCl}$ hydrolyzed the polysaccharide backbone, but at the same time induced a partial removal of the $\mathrm{N}$-acetyl groups. Thus, large reaction times and temperatures led to a product with a large deacetylation degree.

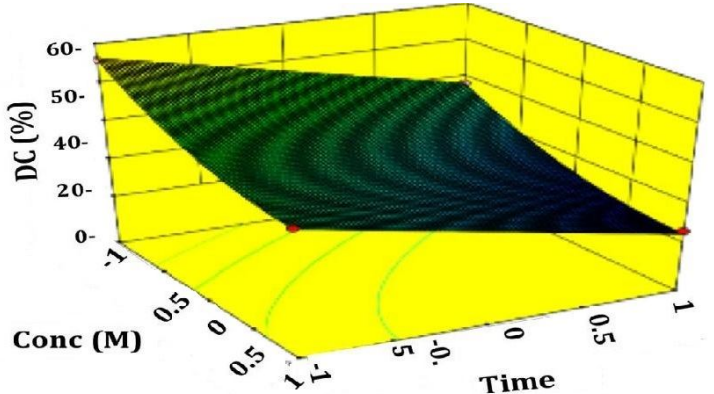

(h)

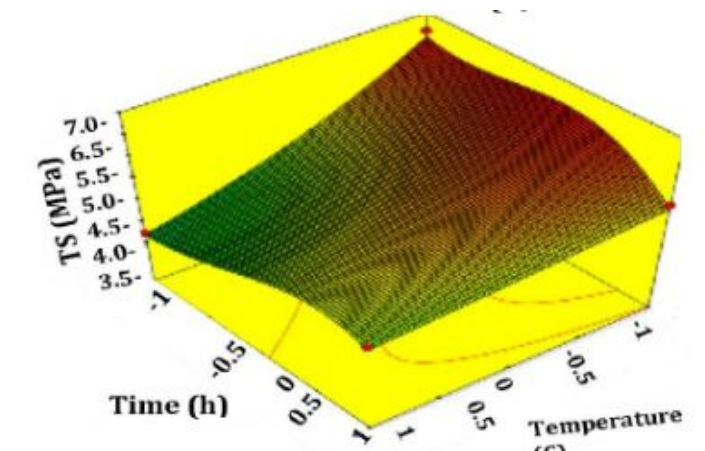

(C)

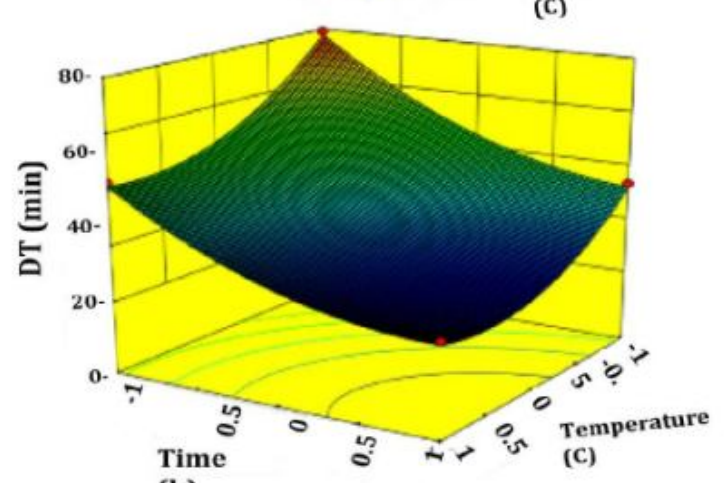

(h)

Figure 2: Surface response plots for (a) DC: degree of crystallinity, (b) TS: tensile strength, and (c) DT: disintegration time

The acid hydrolysis is a non-random depolymerization reaction in which the glycosidic linkage at the non-reducing end group is hydrolyzed more rapidly than other glycosidic linkages in the chain. It is accepted that acid hydrolysis of the glycosidic linkage involves the cleavage of the glycosidic linkage though a SN1 reaction where the rate limiting step is the formation of an activated complex which is a cyclic carbonium-oxonium ion after the protonation. Therefore, the initial step is the protonation of the glycosidic oxygen atom to form a conjugated acid. This is followed by heterolysis of the exocyclic $\mathrm{O}$ to $\mathrm{C}-1$ bond to give a cyclic carbonium-oxonium ion. Further, a reaction with water renders a protonated reducing sugar and from it, the reducing sugar end group is formed. 
Although depolymerization and deacetylation occurred simultaneously, it has been reported that the rate of depolymerization is 10 times larger than the rate of $\mathrm{N}$-deacetylation in concentrated acid, but the two rates are comparable in dilute acid [9].

It is expected that depolymerization reaction happens faster at the terminal bond compared to that of the internal bonds. The introduction of a positive charge in the monomer under acidic conditions makes the depolymerization and the deacetylation processes favorable (Figure 4). It is reported that during the transition state it has a nucleophilic addition on the amide carboxyl group developing a charge on this group. Further, the $\mathrm{N}$-acetyl group contributes to the stabilization of the carbonium ion by forming an oxazoline as an intermediate. The transarrangement of the $\mathrm{C}-2$ and $\mathrm{C}-3$ substituents increases the resistance of the $\mathrm{C}-2$ acetamide group to hydrolysis, so only harsh treatments are required to also achieve deacetylation. In this case, the acid catalyzed cleavage of the $\mathrm{N}$ acetyl-linkage is a SN2 reaction where the rate limiting step is the addition of water to the carbonium ion (Stryer, 1995).

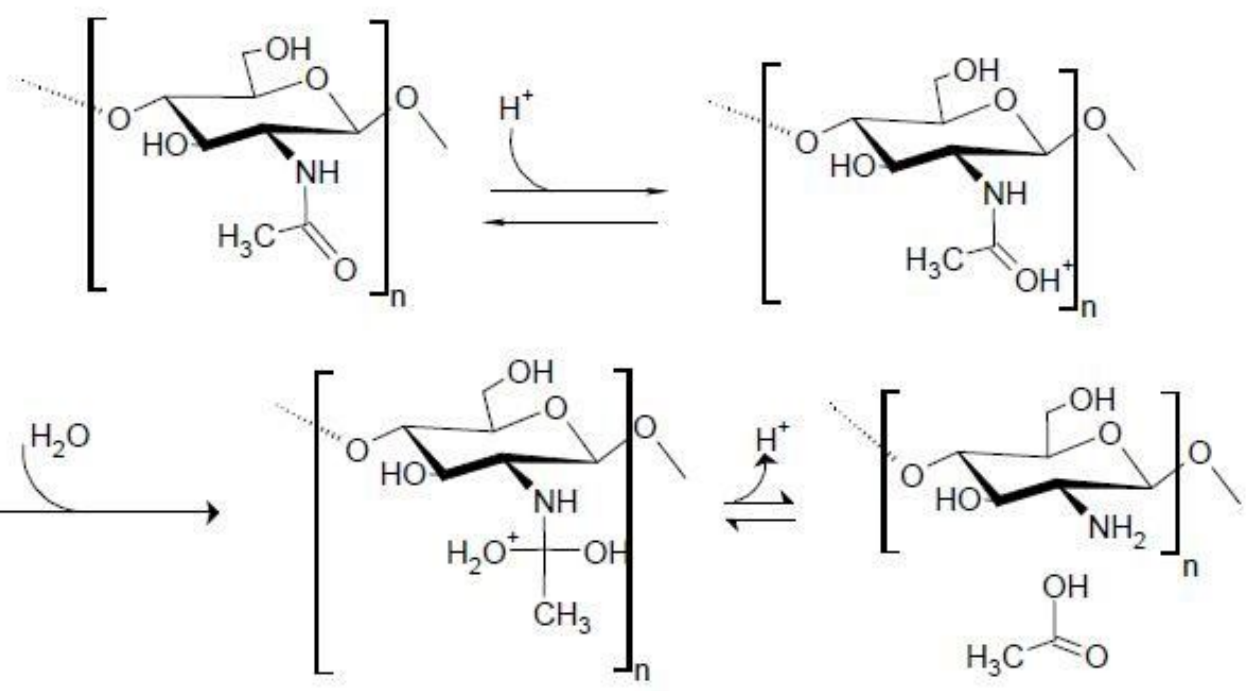

Figure 3: Deacetylation reaction due to acid hydrolysis

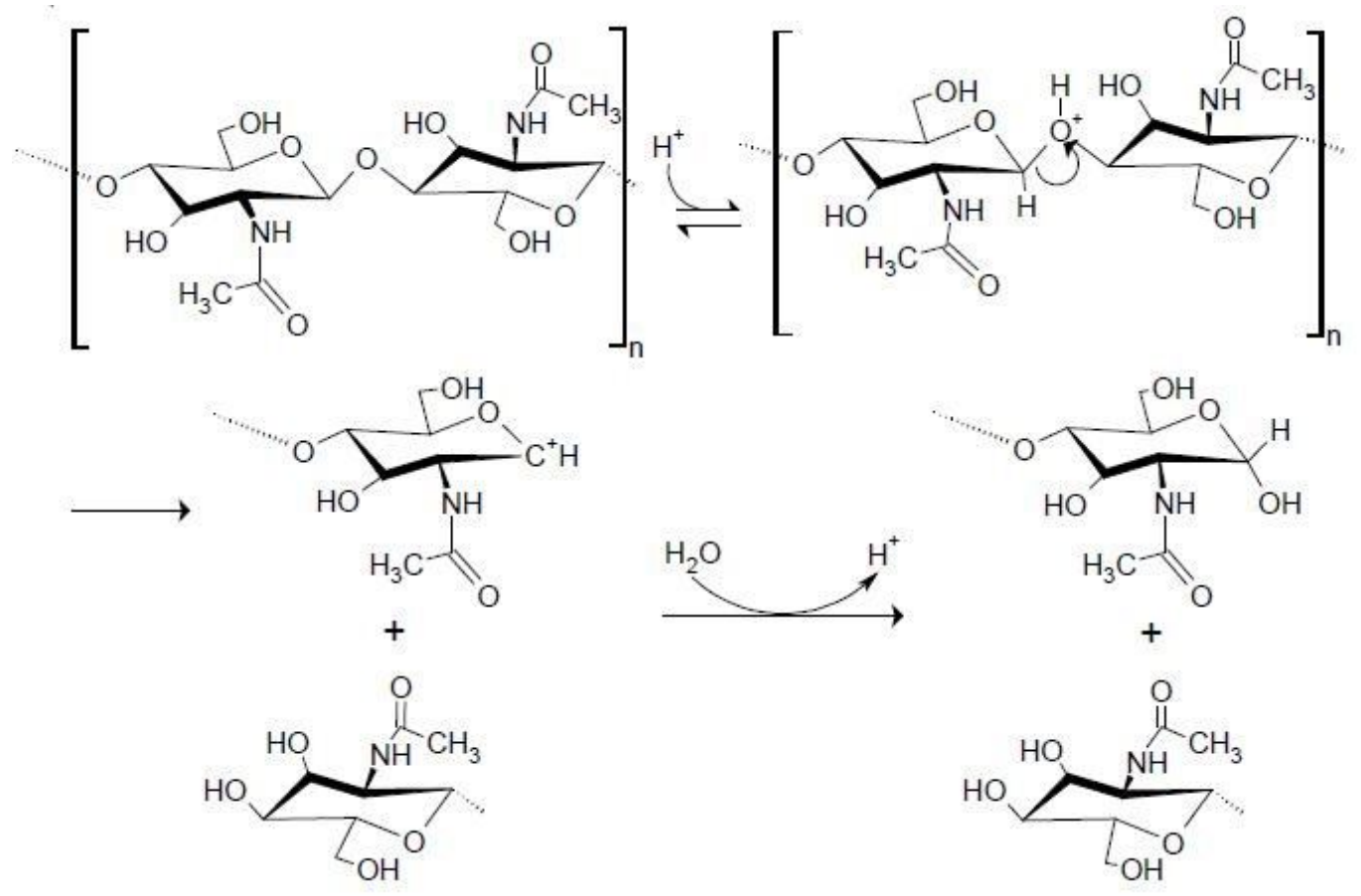

Figure 4: Depolymerization reaction due to acid hydrolysis 
Table 3: Validation of the optimized acid hydrolysis conditions

\begin{tabular}{lcccccc}
\hline Condition & $\begin{array}{c}\text { Yield } \\
\text { (\%) }\end{array}$ & $\begin{array}{c}\text { AD } \\
(\%)\end{array}$ & $\begin{array}{c}\text { TS } \\
\text { (MPa) }\end{array}$ & $\begin{array}{c}\text { DT } \\
\text { (min) }\end{array}$ & $\begin{array}{c}\text { MW } \\
(\mathbf{k D a})\end{array}$ & $\begin{array}{c}\text { DC } \\
(\mathbf{\%})\end{array}$ \\
\hline Model & 11.0 & 54.1 & 5.2 & 27.1 & 78039 & 49.8 \\
Experimental & 10.5 & 58.3 & 5.7 & 25.3 & 83567 & 52.9 \\
\hline
\end{tabular}

Since during acid hydrolysis, chitin swells and $\mathrm{HCl}$ accesses the $\beta-1,4 \quad \mathrm{~N}$-acetyl linkage simultaneously, the net result is a reduction in the crystallinity of the samples. This is due to the deacetylation taking place in the swollen crystallites. It is possible that the hydrolysis process disrupted the intermolecular hydrogen bond pattern of chitin disturbing the regularity of lateral packing between chains. As a consequence, the crystalline structure of chitin is reduced.

In general, chitin yield ranged from $7.2-6.4 \%$ based on the dried shrimp shells. A high yield was obtained at increasing temperatures and low reaction times. This trend was observed independent of the acid concentration used.

It is possible that during the acid hydrolysis polymer degradation is slower in crystalline regions than in amorphous regions. At the same time, the crystallinity of chitin was damaged especially when harsh reaction conditions were employed. Therefore, it is expected a higher molecular weight in samples treated at mild conditions.

Likewise, at moderate hydrolysis conditions, depolymerization reaction increased strongly with increasing acid concentration rendering a low yield of chitin with a low molecular weight. Powder yield decreased with increasing acid concentration since the accessibility of glycosidic linkages to hydrogen is increased by the acidinduced swelling.

The heterogeneous acid hydrolysis involves major depolymerization in the amorphous regions of the polymer leaving almost intact the crystalline native regions in the parent chitin. The acid hydrolysis of the non-crystalline fraction removed chitin blocks of repeated units, especially if they are the crystallite surface and hence, it also reduced the degree of acetylation.

Low and moderate reaction conditions led to a product with a low degree of acetylation and moderate molecular weight with a less tight hydrogen bond network. This was reflected on a powder with better mechanical properties compared to those of materials produced with harsh conditions. On the other hand, high temperatures and long reaction times led to a decrease in compact tensile strength. Perhaps, this was due to the increase in the deacetylation degree. This effect was not observed at low acid concentration.

A high deacetylation and depolymerization prevents the formation of inter and intramolecular hydrogen bonding which is needed for the formation of hard compacts. Therefore, deacetylated products are more prompt to form hydrogen bonds with incoming water molecules and thus disintegration times were faster than those of the acetylated material.

The optimal conditions were found from the grid search of the models to render a chitin with a degree of acetylation from 50-90\%, tensile strength > $5 \mathrm{MPa}$ and disintegration time < 30 min. Compacts with the best tableting properties were obtained when the acid concentration of 2.2 $\mathrm{M}$, temperature of $60{ }^{\circ} \mathrm{C}$ and reaction time of $4 \mathrm{~h}$ and were employed. A validation run was conducted at these conditions and compared to the theoretical values given by the models (Table $3)$.

\section{CONCLUSION}

The acid treatment caused three effects: (a) cleavage of $\beta-1-4$ glycosidic bonds in the main chain of the chitin molecules rendering a smaller degree of polymerization shown by a reduction of the molecular weight, (b) hydrolysis of amide groups resulting in deacetylation (c) cleavage of intra and intermolecular hydrogen bonds leading to alterations chitin crystal structure as demonstrated by the decreased in the degree of crystallinity compact tensile strength. A high deacetylation degree along with a high depolymerization led to a reduction of compact tensile strength and fastened disintegration time making it able to be used as excipient for the development of pharmaceutical dosage forms.

\section{ACKNOWLEDGEMENT}

We greatly thank the committee for the development of research (CODI) and its sustainability strategy (2013-1214) for their financial support. 


\section{REFERENCES}

1. Campana-Filho $S P$, De Britto $D$, Curti E, Abreu FR, Cardoso MB, Battisti MV. Extraction, structures and properties of $\alpha$ - and $\beta$-chitin. Quim Nova 2007; 30: 644-650.

2. Cho Y-W, Jang J, Park CR, Ko S-W. Preparation and solubility in acid and water of partially deacetylated chitins. Biomacromol 2000; 1: 609-614.

3. Yui T, Taki N, Sugiyama J, Hayashi S. Exhaustive crystal structure search and crystal modeling of a-chitin. Int $J$ Biol Macromol 2007; 40: 336-344.

4. Mogilevskaya EL, Akopova TA, Zelenetskii AN, Ozerin AN. The crystal structure of chitin and chitosan. J Appl Polymer Sci Part A 2006; 48: 116-123.
5. Baxter A, Dillon M, Taylor KD, Roberts GAF. Improved method for IR determination of the degree of $N$ acetylation of chitosan. Int J Biol Macromol. 1992; 14: 166-169.

6. Fell JT, Newton J M. Determination of tablet strength by the diametral-compression test. J Pharm Sci 1970; 59: 688-691.

7. Focher B, Beltrame PL, Naggi A, Torri G 1990. Alkaline $\mathrm{N}$-deacetylation of chitin enhanced by flash treatments. Reaction kinetics and structure modifications. Carbohyd Polym, 12, 405-418.

8. Seoudi R, Nada AMA. Molecular structure and dielectric properties studies of chitin and its treated by acid, base and hypochlorite. Carbohyd Polym 2007; 68: 728-733.

9. Varum KM, Ottoy MH, Smidrod O. Acid hydrolysis of chitosans. Carbohyd Polym 2001; 4: 89-98. 